\title{
Anxiety and comfort levels of nursing students
}

\author{
Lemye Aydın ${ }^{1}$, Sebnem Cinar Yucel $^{2}$ \\ 1. Department of Internal Disease of Nursing, Şifa University Faculty of Nursing, İzmir, Turkey. 2. Department of \\ Fundamentals of Nursing, Ege University Faculty of Nursing, İzmir, Turkey. \\ Correspondence: Sebnem Cinar Yucel. Address: Ege University Faculty of Nursing, 35100 Bornova / İzmir, Turkey. \\ Email: sebnem.cinar@ege.edu.tr
}

Received: April 16, 2014

Accepted: June 17, $2014 \quad$ Online Published: June 24, 2014

DOI : $10.5430 /$ jnep.v4n8p179

URL: http://dx.doi.org/10.5430/jnep.v4n8p179

\section{Abstract}

This research was planned to determine the comfort and anxiety levels of the nursing students. In this descriptive study, research population consisted of the students studying in a School of Nursing of a university in the 2011-2012 academic year $(\mathrm{N}=710)$. The students to be included in the sample were selected through stratified sampling method depending on the sizes of classes $(n=221)$. In the research, data were collected through group-type questionnaire method in the classroom environment by using the Student Information Form developed by the researcher, General Comfort Questionnaire (GCQ) and Beck Anxiety Inventory (BAI). It was concluded that the students participating in the research had moderate level of comfort and low level of anxiety.

\section{Key words}

Anxiety, Comfort, Nursing students

\section{I ntroduction}

University life and being a university student generally lead to an environment where anxiety and stress are experienced in Turkey and the other countries ${ }^{[1]}$. University years correspond to a period when the young turn into adults. University students have their own troubles and development problems as individuals. When the young have the opportunity of receiving higher education, they primarily feel pleasure and joy but these positive emotions are usually accompanied by such problems as leaving the family by going another city for studying, entering into a new environment and making new friends, fear of loneliness, economic problems, getting used to living in a dormitory as well as anxiety about the profession and working life in the future. These social, cultural and economic changes may affect the young in an adverse manner psychologically ${ }^{[2,3]}$.

Kolcaba considered comfort as a state resulting from nursing interventions aimed at alleviating or eliminating distress. Comfort is a state in which basic needs related to relief, ease and transcendence are satisfied. Relief is the state of having a specific need met, being necessary for the person to re-establish his/her usual functioning; ease is a state of calm and contentment necessary for effective performance; transcendence is a state in which each person feels they have skills or potential to plan, control their destiny and solve their problems. This type of comfort is also called renewal. These three comfort states develop into four contexts: the physical context relates to bodily sensations; the social context to interpersonal, family and social relationships; the psycho-spiritual context to internal awareness of self, including esteem, concept, sexuality and the meaning of one's life, which may also involve a relationship to a higher order or being; and the 
environmental context which involves aspects such as light, noise, equipment (furniture), colour, temperature and natural versus synthetic elements ${ }^{[4,5]}$.

Anxiety is a state of mind which develops depending on environmental stimulants that are perceived by the individuals as being dangerous or threatening and have unpleasing effects ${ }^{[6]}$. It is well known that anxiety may occur in any period of the life and various situations and conditions can increase the frequency and severity of the anxiety. The adolescence is the period during which the frequency of anxiety reaches the peak. The youth is the period full of conflicts when the individual experiences social and physical changes, is subject to emotional, behavioural, sexual, economic, academic and social conflicts and the efforts exerted to discover the identity intensify. In this period, mental health of the university students constitutes one of the most important components of the community health ${ }^{[7]}$.

Nursing is a health discipline which consists of art and science, has managed to renew itself with social, cultural and technological changes from past to the present, aims at providing sick and healthy individuals of all age groups, families and community with care and is based on philosophy, theory, practice and research ${ }^{[8]}$. In today's world, training qualified nurses has been more important than it was in the past. This is because of the fact that healthcare facilities need more qualified and capable nurses who have command over various areas of knowledge and skills and are highly successful for more efficient functioning, more effective services and easier realisation of the targets and projects. Besides, nurses have been identified as key personnel in the solution of problems in the health system by the national and international documents in the last 30 years. Thus, schools of nursing need to train professional nurses who meet these qualifications and have high levels of success ${ }^{[9]}$.

In a developed country, the most important component of the development is qualified man power. The training of the qualified man power is mostly provided by the universities. The universities which strive at training qualified man power with specific skills and constitute the last ring of the education chain play key roles in the social, cultural, economic, scientific and technological developments of the communities. The future of a country depends on the quality of the universities and, ultimately, the quality of their graduates. There is need for properly determining the psycho-social properties of the young studying in the universities, examining the problems, understanding the reasons of the problems, determining the factors related to the problems and developing approaches that will increase the adaptation potential of the students depending on the obtained information ${ }^{[10]}$.

In the literature there are many studies that analyze the anxiety levels of students in Turkey and around the world ${ }^{[1-23]}$. However when the literature is analyzed, a single study examining the comfort and anxiety levels of nursing students in our country cannot be found. This research was planned to determine the comfort and anxiety levels of the nursing students.

\section{Methods}

\subsection{Place and date of the research}

Research was conducted in a school of nursing found in Izmir, Turkey between March 2011 and April 2011.

\subsection{Population and sample}

In this descriptive study, research population consisted of the students studying in a School of Nursing of a university in the 2011-2012 academic year $(\mathrm{N}=710)$. The students to be included in the sample were selected through stratified sampling method depending on the sizes of classes $(n=221)$. It was also used as convenience sample technique.

Izmir is a large metropolis in the western extremity of Anatolia and the third most populous city in Turkey, following Istanbul and Ankara. The undergraduate nursing program consists of one-year preparatory class in English and four-year 
nursing education in this school found in Izmir. The school admits students from all regions of Turkey and has almost 200 students every year.

\subsection{Data collection}

In the research, data were collected through group-type questionnaire method in the classroom environment by using the Student Information Form developed by the researcher, General Comfort Questionnaire (GCQ) and Beck Anxiety Inventory (BAI).

\subsubsection{Student information form}

The student information Form which was developed by the researchers in line with the literature information includes 9 questions on the introductory information (gender, current grade, age, status of working, status of receiving scholarship, participation in social activities, satisfaction with social support, whether the department of nursing was selected willingly, frequency of meeting with the family) about the students.

\subsubsection{General Comfort Questionnaire (GCQ)}

GCQ is used to determine the requirements of comfort by providing a taxonomic structure where three levels (relief, ease, transcendence) and four dimensions (physical, psycho- spiritual, socio-cultural, environ-mental) constituting the theoretical comopents of the comfort are included. It is a questionnaire which was developed by Kolcaba (1992) (Cronbach's alpha $=0.88$ ) and tested for reliability and validity in Turkey by Kuğuoğlu and Karabacak (2008) (Cronbach's alpha $=0.85$ ). and is composed of 48 items. The highest score to be obtained from the questionnaire is 192 while the lowest score is 48 . The mean value is calculated by dividing the total score obtained from the questionnaire into the number of items and the result is stated in the range of 1-4. A low score means poor comfort while a high score points out to a good comfort ${ }^{[24]}$. In our study, GCQ was found to have adequate internal consistency (Cronbach's alpha $=0.70$ ).

\subsubsection{The Beck Anxiety I nventory (BAI)}

Created by Beck et al., BAI is a 21-question multiple-choice self-report inventory that is used for measuring the severity of an individual's anxiety. The BAI consists of twenty-one questions about how the subject has been feeling in the last week, expressed as common symptoms of anxiety (such as numbness and tingling, sweating not due to heat, and fear of the worst happening). It is designed for an age range of 17-80 years old. Each question has the same set of four possible answer choices, which are arranged in columns and are answered by marking the appropriate one with a cross. The respondent is asked to rate how much he or she has been bothered by each symptom over the past week on a 4-point scale ranging from 0 (not at all) to 3 (severely). Scoring is easily accomplished by summing scores for items. The total score ranges from 0-63. The following guidelines are recommended for the interpretation of scores: 0-9, normal or no anxiety; 10-18, mild to moderate anxiety; 19-29, moderate to severe anxiety; and 30-63, severe anxiety. The BAI is recommended for use in assessing anxiety in clinical and research settings. The validity and reliability study of Turkish version of the scale was made by Ulusoy et al. (1998). Internal consistency is high with Cronbach's alphas ranging from 0.90 to 0.94 and has been tested in large samples of psychiatric patients, college students, and community-dwelling adults ${ }^{[25]}$.

\subsection{Statistical analysis}

Data were analyzed using the Statistical Package for Social Sciences (SPSS) for Windows version 15.0 (SPSS, 2006). Descriptive statistics were used to describe the demographics. For data evaluation; number, percentage, mean, standard deviation, Mann Whitney U, Kruskal Wallis and Student $t$ tests were used. A $p$ value of $<.05$ was considered statistically significant.

\subsection{Ethical considerations}

The research was performed according to the guidelines delineated by the Declaration of Helsinki. Participants in this study voluntarily participated. 


\section{Results}

It was detected that the mean GCQ score of the students participating in the research was $2.68 \pm 0.30$ (min-max: 1.67-3.54) while the mean BAI score was $12.42 \pm 9.41$ (min-max: 0.0-42.00).

While the difference between the BAI score means of nursing students participating in the research by the gender was found to be significant $(p<.05)$, the difference between the GCQ score means was not found to be significant $(p>.05)$ (see Table 1).

Table 1. Comparison of the students with regard to socio-demographic attributes with the mean BAI and GCQ Scores $(\mathrm{n}=221)$

\begin{tabular}{lllll}
\hline & $\mathbf{n}$ & $\mathbf{\%}$ & BAI $\mathbf{X} \pm \mathbf{S S}$ & GCQ $\mathbf{X} \pm \mathbf{S S}$ \\
\hline Gender & 187 & 84.6 & $13.09 \pm 9.35$ & \\
Female & 34 & 15.4 & $8.70 \pm 8.96$ & $2.67 \pm 0.30$ \\
Male & & $t=2.53, p=.01$ & $2.71 \pm 0.30$ \\
& & & $t=-0.62, p=.53$ \\
Education Level & 42 & 19.0 & $15.35 \pm 8.56$ & $2.72 \pm 0.26$ \\
Freshmen & 52 & 23.5 & $10.80 \pm 9.56$ & $2.67 \pm 0.35$ \\
Sophomore & 75 & 52 & $13.82 \pm 9.96$ & $2.62 \pm 0.29$ \\
Junior & 52 & 23.5 & $9.63 \pm 8.17$ & $2.72 \pm 0.28$ \\
Senior & & & $F=4.11, p=.00$ & $F=1.43, p=.23$ \\
& & & & \\
Age & 37 & 16.7 & $13.81 \pm 9.78$ & $2.68 \pm 0.30$ \\
$18-20$ & 137 & 62.0 & $12.06 \pm 8.87$ & $2.69 \pm 0.3$ \\
$20-22$ & 37 & 16.7 & $9.51 \pm 9.05$ & $2.66 \pm 0.27$ \\
$22-24$ & 10 & 4.5 & $22.90 \pm 9.88$ & $2.49 \pm 0.33$ \\
24 and above & & & $\mathrm{KW}=15.48, p=.00$ & $\mathrm{KW}=2.94, p=.40$ \\
& & & $13.36 \pm 12.27$ & $2.75 \pm 0.30$ \\
Status of Working & 19 & 8.6 & $12.33 \pm 9.12$ & $2.67 \pm 0.30$ \\
Working in a job & 202 & 91.4 & $\mathrm{U}=1880.00, p=.88$ & $\mathrm{U}=1642.00, p=.29$ \\
Not working in a job & & & & \\
& & & &
\end{tabular}

The difference between the mean BAI scores of the students by the current grade was found to be significant $(p<.05)$. While the mean BAI score of the 1st grade students was the highest $(15.35 \pm 8.56)$, the mean GCQ $(2.72 \pm 0.26)$ score of the 1st grade students was found to be the lowest (see Table 1).

While the difference between the mean BAI score of the students by the age groups was significant $(p<.05)$, the difference between the mean GCQ scores of the students by the age groups were not found significant $(p>.05)$ (see Table 1).

The differences between the mean BAI and GCQ scores of the students by the variable of working in any job were not found significant $(p>.05)$ (see Table 1).

Differences between the mean BAI and GCQ scores of the students by the variable of receiving scholarship were found to be significant $(p<.05)$ (see Table 2$)$.

Significant difference was found between the mean BAI and GCQ scores of the students by the variable of being satisfied with the social support received $(p<.05)$ (see Table 2). 
Table 2. Comparison of the Students with Regard to Individual Characteristics with the Mean BAI and GCQ Scores (n $=221)$

\begin{tabular}{|c|c|c|c|c|}
\hline & $\mathbf{n}$ & $\%$ & BAI $\mathrm{X} \pm \mathrm{SS}$ & GCQ X \pm SS \\
\hline \multicolumn{5}{|l|}{ Receiving Scholarship } \\
\hline Receiving & 17 & 77.8 & $11.47 \pm 8.89$ & $2.70 \pm 0.30$ \\
\hline \multirow[t]{2}{*}{ Not receiving } & 249 & 22.2 & $15.75 \pm 10.44$ & $2.59 \pm 0.27$ \\
\hline & & & $t=2.18, p=0.03$ & $t=3.51, p=0.00$ \\
\hline \multicolumn{5}{|c|}{ Satisfaction with the Social Support } \\
\hline Satisfied & 123 & 55.7 & $10.17 \pm 7.67$ & $2.74 \pm 0.29$ \\
\hline \multirow[t]{2}{*}{ Not satisfied } & 98 & 44.3 & $15.24 \pm 10.59$ & $2.60 \pm 0.30$ \\
\hline & & & $t=-4.12 \mathrm{p}=0.00$ & $t=3.65, p=0.00$ \\
\hline \multicolumn{5}{|c|}{ Selecting the Department Willingly } \\
\hline Selecting Willingly & 125 & 56.6 & $10.20 \pm 8.19$ & $2.75 \pm 0.31$ \\
\hline \multirow[t]{2}{*}{ Selecting Unwillingly } & 96 & 43.4 & $15.30 \pm 10.13$ & $2.58 \pm 0.26$ \\
\hline & & & $t=-4.13, p=0.00$ & $t=34.17, p=0.00$ \\
\hline \multicolumn{5}{|c|}{ The Frequency of Meeting with the Family } \\
\hline Everyday & 48 & 21.7 & $17.10 \pm 11.24$ & $2.64 \pm 0.31$ \\
\hline Once every week & 4 & 1.8 & $7.25 \pm 5.25$ & $2.80 \pm 0.40$ \\
\hline Once every month & 42 & 19.0 & $10.35 \pm 7.28$ & $2.67 \pm 0.29$ \\
\hline Twice every month & 17 & 7.7 & $14.82 \pm 9.61$ & $2.58 \pm 0.24$ \\
\hline Once every two months & 65 & 29.4 & $10.52 \pm 8.57$ & $2.70 \pm 0.28$ \\
\hline \multirow[t]{2}{*}{ Twice a year/less } & 45 & 20.4 & $11.64 \pm 8.79$ & $2.72 \pm 0.33$ \\
\hline & & & $\mathrm{KW}=14.60, p=0.01$ & $\mathrm{KW}=4.84, p=0.43$ \\
\hline
\end{tabular}

Significant difference was also found between the mean BAI and GCQ scores of the students by the variable of selecting the field willingly $(p<.05)$ (see Table 2$)$.

Whereas the difference between the mean BAI score of the students by the frequency of meeting with their families was reported to be significant $(p<.05)$, the difference between the mean GCQ scores was not found significant $(p>.05)$ (see Table 2).

\section{Discussion}

Comfort is an outcome that is highly desired by patients and their family, and hence represents an important goal of nursing care. Kolcaba defined comfort as "the immediate state of being strengthened through having the human needs for relief, ease, and transcendence addressed in four contexts of experience (physical, psycho-spiritual, socio-cultural and environmental)", and quantified comfort by developing comfort questionnaires. The juxtaposition of the three states of comfort with the four contexts of comfort experience results in a 12-cell grid called the taxonomic structure that has been used in both research and practice. Assessing comfort as a positive, holistic outcome enables nurses to direct their care in ways that are both goal-directed and measurable ${ }^{[26]}$.

In the cities to which the students are strangers, they may alienate to themselves and the traditional order and thus, may spend years with low levels of comfort since they have difficulty in meeting such basic life requirements as receiving social support, being understood, finding shelter, maintaining economic assurance and functional health. While struggling to overcome the problems caused by the low comfort level in their lives and working environments, the young may have psychological problems due to stress and difficulties resulting from various factors. Tuzcuoğlu and Korkmaz (2001) stated in relation to the problems that students in Turkey experience economic, educational, sexual problems as well as problems related to adaptation to school and environment, they cannot find time and opportunity for extracurricular activities, they 
are not provided with adequate guidance for education, they are not trusted and respected and they are subject to excessively tight rules ${ }^{[10]}$.

It is obvious that these problems experienced by the Turkish students have the potential of affecting the comfort in physical, environmental, socio-cultural and psycho-spiritual aspects. This finding supports the low anxiety levels and moderate comfort levels of the students.

It was detected that there was statistically significant difference between the anxiety levels of the students by the variable of gender $(p<.05)$ (see Table 1). It was determined that the anxiety levels of the female participants were high. This finding may be explained by the fact that women are more sentimental than men. It also shows parallelism with the literature ${ }^{[27,28]}$. This finding is attributed to the social gender roles. Comfort levels of the female students $(2.67 \pm 0.30)$ were found lower than the male students $(2.71 \pm 0.30)$ but the difference between them was not statistically significant $(p>.05)($ see Table 1$)$.

The difference between the mean BAI scores of the students by the variable of current grade was found to be significant ( $p$ $<.05)$. It was determined that the 1 st grade nursing students had the highest level of anxiety (15.35 \pm 8.56$)$ (see Table 1). In the study where Wong et al. (2006) examined the students in the first year of the university life in terms of anxiety, it was determined that the anxiety levels of the freshmen were high ${ }^{[29]}$. The first years of the university life is the hardest time for the students. They become subject to a higher level of stress due to numerous factors including adapting to an entirely new environment, trying to internalize the department and transition to adulthood from adolescence ${ }^{[30]}$. The anxiety level decreasing in the sophomores $(10.80 \pm 9.56)$ increases among the juniors once more $(13.82 \pm 9.96)$. In the study where Bayram and Bilgel (2008) examined stress, anxiety and depression prevalence and their relationships with the socio-demographic features, it was found out that the anxiety levels of the freshmen and sophomores were higher than those of the juniors and seniors ${ }^{[31]}$. The difference between two studies is thought to result from the theoretical courses of the 3 rd grade nursing students receiving education with the integrated system rather than the classical system. Among the seniors who complete theoretical education and start to work as intern, the anxiety level decreases (9.63 \pm 8.17 ) (see Table 1). This finding can be explained by the fact that interns have decreased burden of exam, have more opportunities for practising and can improve their practice skills and can adapt to the environment completely.

A significant difference was detected between the mean BAI scores of the students by the variable of age ( $p>.05)$ (see Table 1). It is seen that the anxiety level is inversely proportional to age among the students. This finding is attributed to the fact that students can develop individual coping methods more easily for the problems experienced in the university life with increasing age. However, the highest anxiety level belonged to the group of students aged 24 and above (22.90 \pm 9.88). This high level of anxiety may be explained with the concern of the students for the future in terms of both personal and professional lives within striking distance of graduation.

In this study, the reason why no significant differences were detected in the comfort levels by the variables of age and current grade may be the students of different age groups included in the class (see Table 1).

A significant difference was not found between the anxiety and comfort levels of the students by the variable of working in any job $(p>.05)$ (see Table 1). The mean BAI and GCQ score of the students working in a job was detected as high. It is thought that anxiety levels of the working students due to such problems as work load, responsibility of the professional life and the time constraint but the comfort levels increased as well in parallel to the improving economic conditions.

Significant difference was detected between the mean BAI and GCQ scores of the students by the variable of receiving scholarship $(p<.05)$. It was detected that the anxiety levels of the students receiving scholarship were lower than those not receiving scholarship $(11.47 \pm 8.89)$ while their comfort levels were higher $(2.70 \pm 0.30)$ (see Table 2). Economic problems may increase anxiety levels of the students by affecting their living conditions and decrease their comfort levels. Students of low socio-economic status lack many opportunities such as education, culture and social activities. This may 
cause them to experience high level of anxiety and low level of comfort with the frustration psychology. This finding shows parallelism with the literature ${ }^{[32,33]}$. In a study conducted by Yılmaz and Ocakç1 (2010) on the anxiety levels of the university students, it was detected that $71.5 \%$ of them did not have economic problems owing to their scholarships and thus, suffer from low level of anxiety ${ }^{[34]}$.

As to the variable of being satisfied with the social support received, the mean BAI and GCQ scores were reported to be $10.17 \pm 7.67$ and $2.74 \pm 0.29$, respectively (see Table 2). Sertbaş et al. (2004) examined the relationship between the anxiety level and the perceived social support from the family and friends among the nursing students and reported that the mean score of the students in the social support from the family $(17.83 \pm 2.49)$ was higher than the mean score in the social support from the friends $(16.55 \pm 3.31)$. In the same study, it was determined that the perceived social support and anxiety levels are inversely proportional ${ }^{[35]}$. This finding shows parallelism with the finding of the present study.

A significant difference was detected between the mean BAI and GCQ scores of the students by the variable of selecting the department of nursing willingly $(p<.05)$. It was determined that the anxiety levels of the students selecting the department of nursing willingly were lower $(10.20 \pm 8.19)$ and their comfort levels were higher $(2.75 \pm 0.31)$ (see Table 2). This finding may be explained by the fact that the students studying at the desired departments have fewer concerns for the university and future. Another striking point of the findings is that $43.4 \%$ of the students did not select the department of nursing willingly. In some studies conducted in Turkey, it was reported that a majority of the students studying in the department of nursing did not include this department in their first ten preferences ${ }^{[36-38]}$. In the selection of profession, the public image of the profession is one of the important factors. While many studies emphasize that nursing is an essential and important profession, the problems caused by the public image of nursing in the individuals selecting the profession are expressed. In two different studies carried out on nursing students and nurses, it was emphasized that the perceived image of nursing in the society leads to anxiety in the students.

A significant difference was detected between the main BAI scores of the students by the variable of meeting with the family $(p<.05)$. The students living with the family had the highest anxiety level $(17.10 \pm 11.24)$ and the lowest comfort level $(2.64 \pm 0.31)$ (see Table 2). It is thought that the demands and expectations of the families in Turkey and, in particular, the expectations of the families from the young to lead a life similar to theirs may lead to concerns in the students. Students living with their families may have more comfort than the other students physically but they are limited in terms of environmental, socio-cultural and psycho-spiritual comfort. The finding that the students staying with their families in the weekends had the lowest anxiety level $(7.25 \pm 5.25)$ and the highest comfort level $(2.80 \pm 0.40)$ supports the above-given explanation. This finding shows parallelism with the literature information. In the study where Uzgören (2005) examined the individual characteristics affecting the satisfaction of undergraduates, it was reported that the satisfaction levels of the students living in the same city as their families were lower ${ }^{[39]}$.

\section{Conclusion}

It was concluded that the students participating in the research had moderate comfort and low level anxiety. At the end of the research, it was detected that the anxiety levels of the freshmen, female students, nursing students aged 24 and over were high while the anxiety levels of the students who received scholarship, had social support and selected the department of nursing willingly were low. The comfort levels of the latter group were found to be high. Another finding was that the frequency of meeting with the family and the status of working did not affect the comfort and anxiety levels. By determining the comfort level of the nursing students, besides providing comfort in this direction, eliminating/ minimizing the anxiety and stress will positively affect school success and more attention of nurses' teachers to this issue are recommended. 


\section{References}

[1] Bayram, N., Bilgel, N. The prevalence and socio-demographic correlations of depression, anxiety and stress among a group of university students. Soc Psychiatry PsychiatrEpidemiol. 2008; 43: 667-672. PMid:18398558

http://dx.doi.org/10.1007/s00127-008-0345-x

[2] Çelikel, F.Ç., Erkorkmaz, Ü. Factors associated with depressive symptoms and hopelessness level in university students. Archives of Neuropsychiatry. 2008; 45: 122-129.

[3] Aylaz, R., Kaya, B., Dere, N., Karaca, Z., Bal, Y. The incidence of depression and related factors among health high school students. Anatolian Journal of Psychiatry. 2007; 8: 46-51

[4] Apóstolo, J.L., Kolcaba, K. The effects of guided imagery on comfort, depression, anxiety, and stress of psychiatric inpatients with depressive disorders. Arch Psychiatr Nurs. 2009; 23: 403-11. PMid:19926022 http://dx.doi.org/10.1016/j.apnu.2008.12.003

[5] Apóstolo J, Mendes A, Bath-Hextall F, et al. The use of non-pharmacological nursing interventions on the comfort of cancer patients: A comprehensive systematic review protocol. The JBI Database of Systematic Reviews and Implementation Reports. $2013 ; 11$.

[6] Eysenck, M.W. Anxiety and Cognition: A Unified Theory. Psychology Press, 2014. PMid:24528147

[7] Kaya, M., Genç, M., Kaya, B., Pehlivan, E. The prevalence of depressive symptoms, stress, coping styles and factors affecting in medicine faculty and health high school students. Turkish Journal of Psychiatry. 2007; 18(2): 137-146. PMid:17566879

[8] Özcan, A. Nurse-Patient Relations and Communications. 2006; Ankara, Sistem Ofset, 4-11.

[9] Kocaman, G. Türkiye'de Hemşirelik Eğitim Sorunları ve Çözüm Arayışları (Turkish Nursing Education Problems and Search for Solutions). 2005; Odak publication. Ankara.

[10] Tuzcuoğlu, S., Korkmaz, B. The investigation of levels of submissive behavior and depression of psychological counseling and guidance students. M.Ü. Atatürk Education Faculty Journal of Educational Sciences. 2001; 14: 135-152.

[11] Ahmed, I., Banu, H., Al-Fageer, R., Al-Suwaidi, R. Cognitive emotions: depression and anxiety in medical students and staff. J Crit Care. 2009; 24:e1-7. PMid:19664516 http://dx.doi.org/10.1016/j.jcrc.2009.06.003

[12] Akar, A., Akpolat, D.D., Miman, M. Trait anxiety level analysis of high school students with migration in Mersin. Procedia Social and Behavioral Sciences. 2014; 113: 143-150. http://dx.doi.org/10.1016/j.sbspro.2014.01.021

[13] Amrai, K., Zalani, H.A., Arfai, F.S., Sharifian, M.S. The relationship between the religious orientation and anxiety and depression of students. Procedia Social and Behavioral Sciences. 2011; 15: 613-616. http://dx.doi.org/10.1016/j.sbspro.2011.03.150

[14] Chen, C.S., Lai, C.S., Lu, P.Y., Tsai, J.C., Chiang, H.C., Huang, I.T., Yu, H.S. Performance anxiety at English PBL groups among Taiwanese medical students: a preliminary study. Kaohsiung J Med Sci. 2008; 24:54-8. http://dx.doi.org/10.1016/S1607-551X(08)70095-0

[15] Chen, Y., Yang, X., Wang, L., Zhang, X. A randomized controlled trial of the effects of brief mindfulness meditation on anxiety symptoms and systolic blood pressure in Chinese nursing students. Nurse Educ Today. 2013; 33:1166-72. PMid:23260618 http://dx.doi.org/10.1016/j.nedt.2012.11.014

[16] Dalbudak, E., Evren, C., Aldemir, S., Coskun, K.S., Yıldırım, F.G., Ugurlu, H. Alexithymia and personality in relation to social anxiety among university students. Psychiatry Res. 2013; 209: 167-72. PMid:23246382 http://dx.doi.org/10.1016/j.psychres.2012.11.027

[17] Dehghan-Nayeri, N., Adib-Hajbaghery, M. Effects of progressive relaxation on anxiety and quality of life in female students: a non-randomized controlled trial. Complement Ther Med. 2011; 19: 194-200. PMid:21827933 http://dx.doi.org/10.1016/j.ctim.2011.06.002

[18] Gibbons, C. Stress, coping and burn-out in nursing students. Int J Nurs Stud. 2010; 47(10): 1299-309. PMid:20359710 http://dx.doi.org/10.1016/j.ijnurstu.2010.02.015

[19] Hosseinia, L., Khazalib, H. Comparing the level of anxiety in male \& female school students. Procedia - Social and Behavioral Sciences. 2013; 84: 41-46. http://dx.doi.org/10.1016/j.sbspro.2013.06.506

[20] Kang, Y.S., Choi, S.Y., Ryu, E. The effectiveness of a stress coping program based on mindfulness meditation on the stress, anxiety, and depression experienced by nursing students in Korea. Nurse Educ Today. 2009; 29:538-43. PMid:19141364 http://dx.doi.org/10.1016/j.nedt.2008.12.003

[21] Niusha, B., Farghadani, A., Safari, N. Effects of assertiveness training on test anxiety of girl students in first grade of guidance school. Procedia - Social and Behavioral Sciences. 2012; 46: 1385-1389. http://dx.doi.org/10.1016/j.sbspro.2012.05.307

[22] Suliman, W.A., Halabi, J. Critical thinking, self-esteem, and state anxiety of nursing students. Nurse Educ Today. $2007 ; 27: 162-8$. PMid:16857300 http://dx.doi.org/10.1016/j.nedt.2006.04.008

[23] Yusoff, M.S., Abdul Rahim, A.F., Baba, A.A., Ismail, S.B., Mat Pa, M.N., Esa, A.R. Prevalence and associated factors of stress, anxiety and depression among prospective medical students. Asian J Psychiatr. 2013; 6: 128-33. PMid:23466109 http://dx.doi.org/10.1016/j.ajp.2012.09.012 
[24] Kuğuoğlu, S., Karabacak, U. The Turkish adaptation of General Comfort Questionnaire. IU Florance Nigtingale Journal of Nursing. 2008; 16, 16-23.

[25] Ulusoy, M., Şahin, N.H., Erkmen, H. Turkish Version of the Beck Anxiety Inventory: Psychometric Properties Journal of Cognitive Psychotherapy. An International Quarterly. 1998; 12 (2): 21-28.

[26] Kim, K.S., Kwon, S.H. Comfort and quality of life of cancer patients. Asian Nursing Research. 2007; 1: 125-135. http://dx.doi.org/10.1016/S1976-1317(08)60015-8

[27] Y1lmaz, E., Y1lmaz, E., Karaca, F. The examination of social support and loneliness levels of university students. Journal of General Medicine. 2008; 18(2): 71-79.

[28] Canbaz, S., Sünter, A.T., Aker, S., Peşken, Y. Anxiety level and affecting factors of medicine faculty last year students. Journal of General Medicine. 2007; 17(1): 15-19.

[29] Wong, J.G., Cheung, E.P., Chan, K.K., Ma, K.K., Tang, S.W. Web-based survey of depression, anxiety and stress in first-year tertiary education student in Hong Kong. Aust N Z J Psychiatry. 2006; 40(9): 777-782. PMid:16911753 http://dx.doi.org/10.1080/j.1440-1614.2006.01883.x

[30] Okanl1, A. Relationship between perceived social support from family and friends and anxiety level of nursing students. Ataturk University Health Sciences Institute Master's Thesis. Erzurum. 1999.

[31] Bayram, N., Bilgel, N. The prevalence and socio-demographic correlations of depression, anxiety and stress among a group of university students. Soc Psychiatry Psychiatr Epidemiol. 2008; 43: 667-672. PMid:18398558 http://dx.doi.org/10.1007/s00127-008-0345-x

[32] Cenkseven, F. The examining predictors of subjective and psychological well-being in university students. Unpublished doctoral dissertation, Çukurova University Social Sciences Institute. Adana. 2004.

[33] Gündoğar, D., Gül, S.S., Uskun, E., Demirci, S., Keçeci. D. The investigation of predictors factors of life satisfaction in college students. Clinical Psychiatry. 2007; 10: 14-27.

[34] Yılmaz, M.,Ocakç1, A.F. The determination of university students' anxiety levels in a girls dormitory. Maltepe University Journal of Nursing Science and Art. 2010; 3: 15-23.

[35] Sertbas, G., Çuhadar, D., Demirli, F. The determining of relationship between perceived social support from family and friends and anxiety level in health school department of nursing students in Gaziantep University. Nursing Forum. 2004; 42-48.

[36] Kuzulu, K., Koçak, F. The factors affecting orient to the profession and their value system of first students in Hacettepe University School of Nursing, the 3rd International Participatory Nursing Education Symposium (Proceedings) September, İstanbul 120-128. 1997.

[37] Sezgin, A., Yalçınkılıç, G. The relationship between level of knowledge opinions about nursing profession and school success level and the level of and change of Cumhuriyet University School of Nursing Students. 3rd International Participatory Nursing Education Symposium (Proceedings). September, İstanbul. 130-140. 1997.

[38] Yanıkkerem, E., Altıparmak, S., Karadeniz, G. Factors affecting the career choice of young people and self-esteem: Manisa School of Health Case. Journal of Nursing Forum. 2004; 7(2): 60-67.

[39] Uzgören, N., Uzgören, E. Dumlupınar University Undergraduate Students' statistical analysis of individual characteristics affecting satisfaction. Dumlupınar University Journal of Social Sciences. 2007; 17: 173-192. 